\title{
Large cell neuroendocrine carcinoma: An aggressive form of non-small cell lung cancer
}

\author{
Richard J. Battafarano, MD, PhD, ${ }^{a}$ Felix G. Fernandez, MD, John Ritter, MD, ${ }^{\text {b }}$ Bryan F. Meyers, MD, \\ Tracey J. Guthrie, RN, ${ }^{a}$ Joel D. Cooper, MD, and G. Alexander Patterson, MD ${ }^{a}$
}

From the Department of Surgery, Division of Cardiothoracic Surgery, and the Department of Pathology, ${ }^{b}$ Washington University School of Medicine, St Louis, Mo.

Read at the Eighty-fourth Annual Meeting of The American Association for Thoracic Surgery, Toronto, Ontario, Canada, April 25-28, 2004.

Received for publication April 22, 2004; revisions received Feb 1, 2005; accepted for publication Feb 24, 2005.

Address for reprints: Richard J. Battafarano, MD, PhD, 1 Barnes-Jewish Plaza, 3108 Queeny Tower, St Louis, MO 63110-1013 (E-mail: battafarano@msnotes.wustl.edu).

J Thorac Cardiovasc Surg 2005;130:166-72

$0022-5223 / \$ 30.00$

Copyright $\odot 2005$ by The American Association for Thoracic Surgery

doi:10.1016/j.jtcvs.2005.02.064
Objective: Large cell neuroendocrine carcinomas of the lung display morphologic and immunohistochemical characteristics common to neuroendocrine tumors and the morphologic features of large cell carcinomas. Surgical resection of large cell neuroendocrine carcinomas in many series has been described, with 5 -year actuarial survivals ranging from $13 \%$ to $57 \%$. Considerable debate has emerged as to whether these tumors should be classified and treated as nonsmall cell lung cancers or small cell lung cancers. The objective of this study was to report the outcome of surgical resection in patients with large cell neuroendocrine carcinomas.

Methods: An analysis of our tumor registry was performed to identify all patients undergoing surgical resection of lung cancer between July 1, 1988, and December 31, 2002, for large cell tumors. Cases were then segregated into large cell neuroendocrine carcinomas, mixed large cell neuroendocrine carcinomas (in which at least one portion of the tumor was a large cell neuroendocrine carcinoma), or large cell carcinomas on the basis of morphology and differentiation. Follow-up was complete on all patients, with a mean follow-up of 48 months. Type of resection, mortality, and survival by stage were analyzed. Kaplan-Meier survival was determined for all patients from the date of surgical intervention. Cox proportional hazards model analysis incorporating the variables of age, sex, histology, and stage estimated the effect of large cell neuroendocrine carcinomas and mixed large cell neuroendocrine carcinomas on recurrence and death. The stage of disease in all patients was assessed according to the 1997 American Joint Committee on Cancer guidelines.

Results: Of the 2099 patients who underwent resection, 82 (3.9\%) had large cell lung cancers. Perioperative mortality was $2.4 \%$. Overall survival and freedom from recurrence at 5 years for the entire group was $47.1 \%$ and $58.4 \%$, respectively. Overall survival by histologic subtype at 5 years was $30.2 \%$ for patients with large cell neuroendocrine carcinomas $(n=45), 30.3 \%$ for patients with mixed large cell neuroendocrine carcinomas $(n=11)$, and $71.3 \%$ for patients with large cell carcinomas $(n=21)$. Survival was significantly worse for patients with large cell neuroendocrine carcinomas than for patients with large cell carcinomas $(P=.013)$. The presence of large cell neuroendocrine carcinomas in the specimen (the large cell neuroendocrine carcinoma and mixed large cell neuroendocrine carcinoma groups combined) was significantly associated with decreased survival (relative risk, 2.44; $95 \%$ confidence interval 1.29-4.58; $P=.003$ ) and decreased freedom from recurrence (relative risk, 4.52; 95\% confidence interval, 1.76-11.57; $P<.001)$.

Conclusion: Patients with large cell neuroendocrine carcinomas have a significantly worse survival after resection than patients with large cell carcinomas, even in stage I disease. Accurate differentiation of large cell neuroendocrine carcinoma from large cell carcinoma is important because it identifies those patients at highest risk for the development of recurrent lung cancer. 
$\mathrm{L}$ arge cell neuroendocrine carcinomas (LCNECs) of the lung display the morphologic and immunohistochemical characteristics common to neuroendocrine tumors and the morphologic features of large cell carcinomas (LCCs). The 1999 World Health Organization International Association for Staging of Lung Cancer histologic classification of lung and pleural tumors grouped a number of histologic variants under the heading "large cell carcinoma," including LCNEC, combined LCNEC, basaloid carcinoma, lymphoepithelioma-like carcinoma, clear cell carcinoma, and LCC with rhabdoid phenotype. ${ }^{1}$ Although this classification scheme placed all lung cancers with large cell characteristics in a separate category, it did not address the biologic behavior of these histologic variants.

Travis and colleagues ${ }^{2}$ proposed a separate category of pulmonary neuroendocrine tumors in which LCNEC was distinct from typical carcinoid tumors, atypical carcinoid tumors, and small cell lung cancer (SCLC). LCNEC was described as having a cell size at least 3 times that of SCLC, an organoid growth pattern, cellular palisading or rosettelike areas, a high mitotic rate, and a variably granular chromatin pattern. ${ }^{3}$ The spectrum of neuroendocrine tumors was further classified by Dressler and associates ${ }^{4}$ on the basis of histologic characteristics and clinical behavior. Grade I neuroendocrine lung cancers corresponded to classic typical carcinoid tumors. Grade II neuroendocrine lung cancers corresponded most closely with atypical carcinoid cancers. Grade III tumors were divided into small cell neuroendocrine lung cancer (SCLC) and LCNEC. Regardless of which classification scheme is preferred, accurate differentiation of LCNEC from other variants of non-small cell lung cancer (NSCLC) and SCLC might be difficult and often requires specific immunohistochemical stains for neuroendocrine markers.

The true incidence of LCNEC is in all probability very low, although it has not been well defined. In a series reported by Jiang and coworkers ${ }^{5}$ of 766 resected primary lung cancers, 22 (2.9\%) were classified as LCNECs. Takei and colleagues ${ }^{6}$ reported a similar rate of $3.1 \%(87 / 2790)$ in their series. In published series the overall 5-year actuarial survivals for surgically resected LCNEC range from $13 \%$ to $57 \%$ (Table 1). ${ }^{3-11}$ These results appear to be substantially worse than those observed in other histologic types of NSCLC. Therefore, considerable debate has emerged as to whether these tumors should be classified and treated as NSCLC or considered together with small cell carcinoma because of their apparent aggressive behavior. The objective of this study was to examine the effect of LCNEC on survival after surgical resection in patients with this histologic subtype of NSCLC.

\section{Methods}

\section{Population Under Study}

The Barnes-Jewish Hospital Cancer Registry and the Thoracic Surgery database were queried for patients undergoing surgical
TABLE 1. Previous series examining overall survival for LCNEC

\begin{tabular}{lcccc}
\hline \multicolumn{1}{c}{ Author } & Year & $\begin{array}{c}\text { No. of } \\
\text { patients }\end{array}$ & 5-year 0S & $\begin{array}{c}\text { 5-year 0S } \\
\text { stage I (n) }\end{array}$ \\
\hline Dressler et al & 1997 & 40 & $13 \%$ & $18 \%(25)$ \\
Travis et al $^{4}$ & 1998 & 37 & $27 \%$ & $\mathrm{NA}$ \\
Jiang et al $^{5}$ & 1998 & 22 & $44.8 \%$ & $\mathrm{NA}$ \\
Garcia-Yuste et al $^{8}$ & 2000 & 22 & $21 \%$ & $33 \%(13)$ \\
lyoda et al $^{7}$ & 2001 & 50 & $\sim 35 \% *$ & $\mathrm{NA}$ \\
Zacharias et al $^{9}$ & 2003 & 20 & $47 \%$ & $88 \%(9)$ \\
Takei et al $^{6}$ & 2003 & 87 & $57 \%$ & $67 \%(41)$ \\
Paci et al & 2004 & 48 & $21 \%$ & $27 \%(29)$ \\
Doddoli et al & 2004 & 20 & $36 \%$ & $\mathrm{NA}$ \\
\hline
\end{tabular}

$\overline{L C N E C \text {, Large cell neuroendocrine carcinoma; } O S \text {, overall survival; } N A \text {, not }}$ applicable. *Number estimated from survival curve.

resection of lung cancer between July 1, 1988, and December 31, 2002, for large cell tumors. All slides of LCCs encountered during that time were individually reviewed by one pathologist (J.H.R.) and segregated into the categories of LCNEC, mixed LCNEC (in which at least one portion of the tumor was LCNEC), or LCC on the basis of morphology and differentiation. The pathologist was blinded to the clinical data associated with the pathologic specimens. Surgical pathology reports of all patients selected from this database query were individually reviewed, and the final pathologic staging was assigned according to the 1997 revisions in the International System for Staging Lung Cancer. ${ }^{12}$

Tumor recurrence, patient survival, and cause of death were determined for each patient. Follow-up information, including cause of death, was acquired within the last 6 months for all patients through clinic follow-up notes, direct patient or family contact, contact with the patient's primary care physician, and review of all death certificates. This study represents a secondary data analysis of a prospective cohort study. Approval for this study was granted from the Washington University School of Medicine Human Studies Committee.

\section{Statistical Analysis}

Descriptive statistics were used to describe the patients' characteristics and outcomes. Kaplan-Meier (product limit) graphs were used to demonstrate survival over time and freedom from recurrence of disease. Survival and event-free survival comparisons between groups of patients were completed by the MantelHaenszel log-rank test. The Cox multivariate proportional hazards regression model was used to identify independent risk factors for death and recurrence in the studied patient population, including the variables of age, sex, histology, and stage. All data analysis was performed with SPSS (SPSS 11.0 for Windows; SPSS, Inc, Chicago, Ill).

\section{Results}

\section{Patient Demographics}

Of 2089 patients undergoing resection for NSCLC between July 1, 1988, and December 31, 2002, 82 (3.9\%) had large cell lung cancers. Of these 82 cancers, 45 (54.9\%) were 
TABLE 2. Pathologic staging on the basis of tumor histology

\begin{tabular}{lccc}
\hline Stage & LCNEC & Mixed LCNEC & LCC \\
\hline I & $30(66.7 \%)$ & $3(27.3 \%)$ & $21(80.8 \%)$ \\
II & $11(24.4 \%)$ & $4(36.4 \%)$ & $4(15.4 \%)$ \\
III & $3(6.7 \%)$ & $4(36.4 \%)$ & $1(3.8 \%)$ \\
IV & $1(2.2 \%)$ & 0 & 0 \\
\hline
\end{tabular}

$\angle C N E C$, Large cell neuroendocrine carcinoma; $L C C$, large cell carcinoma.

classified as LCNEC, $26(31.7 \%)$ as LCC, and 11 (13.4\%) as mixed LCNEC. Forty-six (56\%) patients were male, and $36(44 \%)$ were female. The median patient age was 67 years (range, 35-90 years). Operative procedures performed included 69 lobectomies $(84.1 \%), 6$ wedge resections $(7.3 \%)$, 4 pneumonectomies (4.9\%), 2 sleeve resections (2.4\%), and 1 segmentectomy (1.2\%). Two (2.4\%) patients had residual microscopic disease at the margin after surgical resection. The distribution of patients by pathologic stage was 54 $(65.9 \%)$ in stage I, $19(23.2 \%)$ in stage II, 8 (9.8\%) in stage III, and $1(1.2 \%)$ in stage IV. Stage distribution according to tumor histology is shown in Table 2. A comparison in stage distribution between LCNEC and NSCLC treated during the study period is shown in Table 3. No patients received preoperative chemotherapy or radiation therapy. However, 14 patients with greater than stage I disease received adjuvant therapy: LCNEC (8/45), LCC (1/26), and mixed $(5 / 11)$.

\section{Survival}

Survival data were collected for each patient from the date of operation, with a mean duration of follow-up of 52.8 months. The 5-year actuarial overall survival for the entire group was $47.1 \%$. Survival for patients with LCNEC was significantly lower than that observed in patients with LCC (30.2\% vs $71.3 \%, P=.013$, Figure 1 ). This significant difference in survival was also seen in patients with stage I disease $(32.1 \%$ vs $80.0 \%, P=.008$, Figure 2$)$. Although the number of patients with mixed LCNEC was small, the survival observed in these patients appeared to be similar to that of patients with LCNEC.

The association of age, sex, tumor histology, and pathologic stage with survival was analyzed by Cox proportional hazard multivariate analysis. As shown in Table 4, patients with LCNEC and mixed LCNEC were 2.4 times more likely

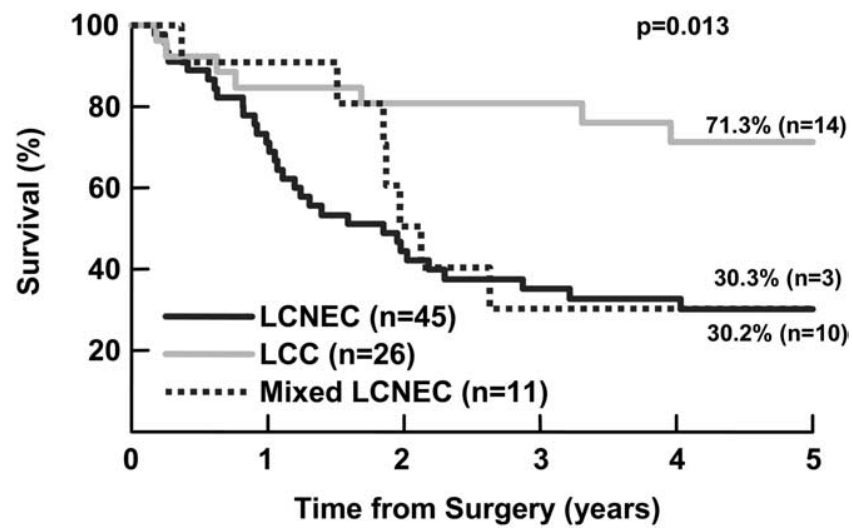

Figure 1. Kaplan-Meier overall survival stratified by cell type.

to die during the follow-up period than were patients with LCC (relative risk, 2.44; 95\% confidence interval, 1.294.58; $P=.003)$.

\section{Causes of Death}

Two $(2.4 \%)$ patients died in the early postoperative period, and $54(65.9 \%)$ additional patients died during follow-up. Of 56 mortalities in this series, 38 were the result of metastatic disease, 11 were from cardiac disease, 6 were from respiratory failure, and 1 was from injuries sustained during a motor vehicle collision.

\section{Incidence of Recurrent Lung Cancer}

Forty (48.8\%) patients had recurrent lung cancer during the follow-up period. Five-year actuarial freedom from recurrence for patients with LCNEC was significantly lower than that observed in patients with LCC $(39.3 \%$ vs $83.8 \%, P=$ .003 , Figure 3 ). This significant difference in freedom from recurrence was also seen in patients with stage I disease $(43.5 \%$ vs $90.0 \%, P=.004$, Figure 4$)$. Freedom from recurrence in patients with mixed LCNEC was similar to that observed in patients with LCNEC.

The association of age, sex, tumor histology, and pathologic stage with survival was analyzed by Cox proportional hazard multivariate analysis. As shown in Table 5, patients with LCNEC and mixed LCNEC were 4.5 times more likely to have recurrent lung cancer during the follow-up period than were patients with LCC (relative risk, 4.52 ; 95\% confidence interval, 1.76-11.57; $P<.001$ ).

TABLE 3. Distribution of stages for resected patients with LCNEC versus NSCLC

\begin{tabular}{lccccrrr}
\hline & IA & IB & IIA & IIB & IIIA & IIIB & IV \\
\hline NSCLC ( $\mathrm{n}=2089)$ & $34.4 \%$ & $23.8 \%$ & $3.4 \%$ & $16.1 \%$ & $13.9 \%$ & $5.3 \%$ & $3.1 \%$ \\
LCNEC ( $\mathrm{n}=45)$ & $48.8 \%$ & $17.9 \%$ & $4.4 \%$ & $20.0 \%$ & $6.7 \%$ & $0 \%$ & $2.2 \%$ \\
\hline
\end{tabular}

LCNEC, Large cell neuroendocrine carcinoma; NSCLC, non-small cell lung carcinoma. 


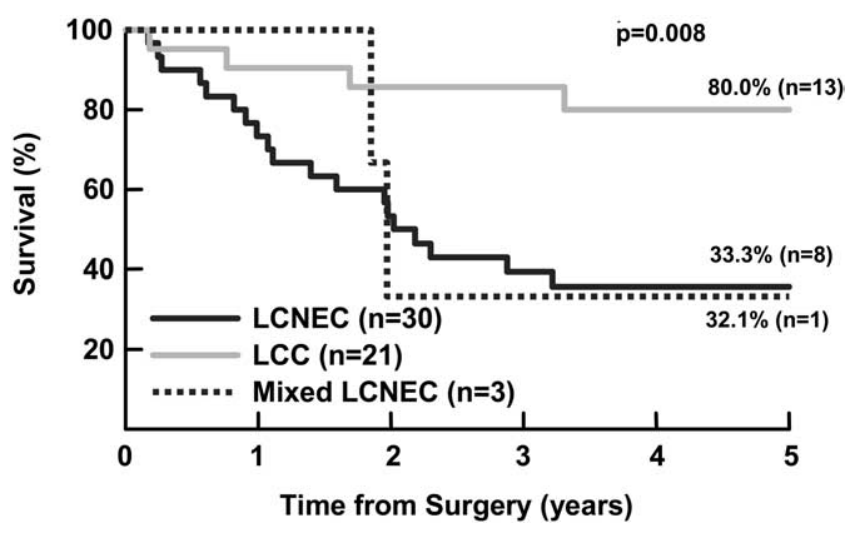

Figure 2. Kaplan-Meier overall survival stratified by cell type: stage I only.

\section{Discussion}

The morphologic and phenotypic features that distinguish LCNEC from other histologic subtypes of NSCLC have been well described. Because survival after resection in patients with LCNEC has been disappointingly low, there has been considerable debate as to whether these tumors should be classified and treated as NSCLCs or considered together with SCLCs. The incidence of LCNEC in our series of resected lung cancers was $2.2 \%$, and this figure is in agreement with those reported in other series. ${ }^{4-6,13}$ The overall 5-year survival for patients with LCNEC treated with surgical resection was $30 \%$, which was significantly lower than the survival observed in patients with LCC, with no evidence of neuroendocrine morphology or differentiation. Importantly, this significant difference was observed even in patients with stage I disease, demonstrating the negative effect of LCNEC histology on survival.

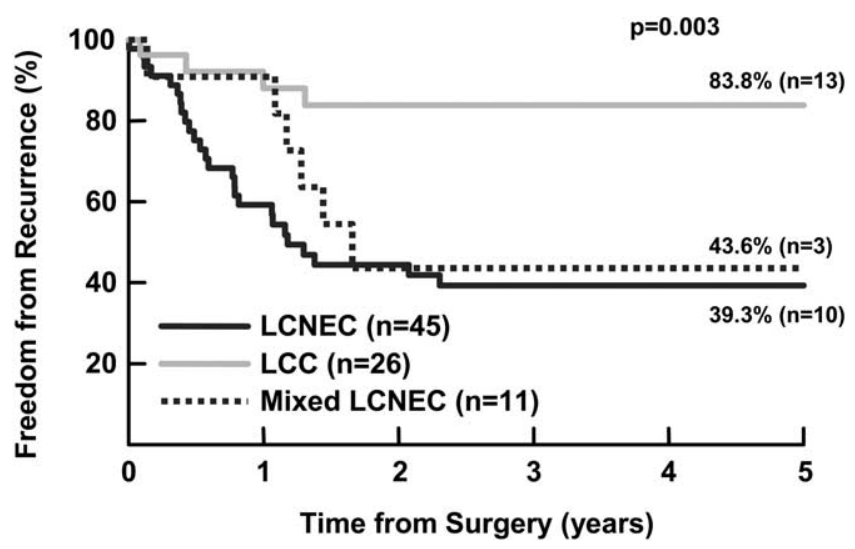

Figure 3. Kaplan-Meier recurrence-free survival stratified by cell type.

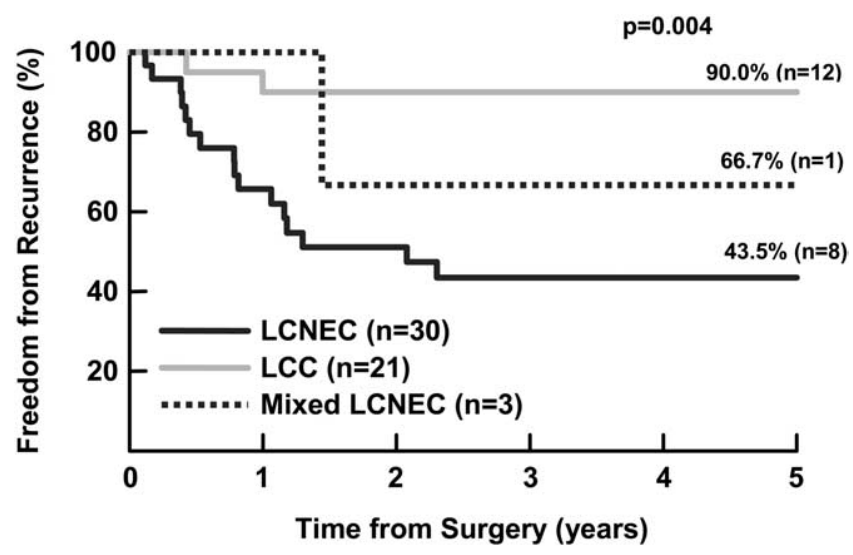

Figure 4. Kaplan-Meier recurrence-free survival stratified by cell type: stage I only.

Although a wide range of 5-year survivals has been reported for resected stage I LCNEC (18\% to $88 \%$ ), ${ }^{4,6,8-10}$ the $32 \% 5$-year survival observed in this series for stage I disease is very similar to that seen in the studies reported by Garcia-Yuste and coworkers ${ }^{8}(33 \%)$ and Paci and colleagues $^{10}(27 \%)$. Both Takei and associates ${ }^{6}$ and Zacharias and coworkers ${ }^{9}$ have reported higher 5-year survivals $(67 \%$ and $88 \%$, respectively) after surgical resection in patients with LCNEC. The reasons for the wide variation in survival

TABLE 4. Results of multivariate analysis of prognostic factors influencing survival for patients after surgical resection

\begin{tabular}{|c|c|c|c|c|}
\hline Variable & $\mathbf{N}$ & Relative risk & $95 \% \mathrm{Cl}$ & $P$ value \\
\hline $\begin{array}{l}\text { Cell type (LCNEC/mixed } \\
\text { LCNEC) }\end{array}$ & 56 & 2.436 & $1.294-4.584$ & .003 \\
\hline Age (y) & 82 & 1.021 & $1.011-1.048$ & .010 \\
\hline $\begin{array}{l}\text { Stage of disease } \\
\text { (stage II, III, or IV) }\end{array}$ & 28 & 1.354 & $0.757-2.423$ & .314 \\
\hline Sex (female) & 36 & 1.192 & $0.690-2.061$ & .526 \\
\hline
\end{tabular}

TABLE 5. Results of multivariate analysis of prognostic factors influencing disease recurrence for patients after surgical resection

\begin{tabular}{|c|c|c|c|c|}
\hline Variable & $\mathbf{N}$ & Relative risk & $95 \% \mathrm{CI}$ & $P$ value \\
\hline $\begin{array}{l}\text { Cell type (LCNEC/mixed } \\
\text { LCNEC) }\end{array}$ & 56 & 4.515 & $1.763-11.565$ & $<.001$ \\
\hline Age $(y)$ & 82 & 1.010 & $0.979-1.043$ & .129 \\
\hline $\begin{array}{l}\text { Stage of disease } \\
\text { (stage II, III, or IV) }\end{array}$ & 28 & 1.611 & $0.853-3.042$ & .145 \\
\hline Sex (female) & 36 & 1.641 & $0.854-3.152$ & .533 \\
\hline
\end{tabular}

$\mathrm{Cl}$, Confidence interval; $L C N E C$, large cell neuroendocrine carcinoma. 
in patients with LCNEC are unclear. Zacharias and coworkers $^{9}$ attributed the excellent survival observed in their study to the use of systematic nodal dissection at the time of resection. However, this study was relatively small (20 patients), and the 88\% 5-year survival for stage I LCNEC reported in this series was based on 9 patients.

Although the diagnosis of LCNEC can be easily made when lung tumors have evidence of both neuroendocrine morphology and differentiation, there often is some hesitancy among pathologists to ascribe the diagnosis of LCNEC if tumors exhibit only neuroendocrine morphology or differentiation but not both. In this series, large cell lung tumors that demonstrated either neuroendocrine morphology or differentiation (or both) were considered LCNEC. Mixed LCNEC tumors were tumors that contained areas of LCNEC and other histologic subtypes of NSCLC, such as adenocarcinoma. Although there were only 11 patients in this series with mixed LCNEC, these tumors were associated with a 5-year survival that was similar to that for pure LCNEC and significantly worse than that for LCC. The finding that mixed LCNEC appears to have the same clinical behavior as LCNEC has also been observed by others. ${ }^{4,7,9,14}$ However, one group found that LCCs with neuroendocrine features had a prognosis similar to that of other histologic subtypes of NSCLC. ${ }^{15}$ At the cellular level, LCNEC has a higher proliferative activity than does LCC, ${ }^{16,17}$ and expression analysis of p53, Ki-67, K-ras-2, and C-raf-1 suggested that LCNECs are genetically and immunohistochemically more similar to SCLCs than NSCLCs. ${ }^{18,19}$ These observations might be explanations for the unfavorable tumor biology associated with LCNEC.

Because of the significantly poorer prognosis associated with LCNEC and mixed LCNEC in comparison with LCC, we believe that these histologic variants of NSCLC should be carefully distinguished pathologically by both light microscopy and immunohistochemical staining for neuroendocrine markers. Identification of somatostatin receptors on LCNEC in vivo with OctreoScan, indium 11-tagged diethylenetriamine pentaacetic acid pentreotide scintigraphy, ${ }^{20-22}$ might represent an opportunity to improve preoperative staging when LCNEC is suspected or confirmed, as well as screening for tumor recurrence postoperatively. ${ }^{23}$ Treatment of patients with the somatostatin analog octreotide after surgical resection might also represent a novel adjuvant biologic therapy because it has been shown to control metastatic growth while being well tolerated in the treatment of other neuroendocrine tumors. ${ }^{24}$ However, this potential therapy might be limited because Jiang and colleagues ${ }^{5}$ identified somatostatin receptor expression by immunohistochemical staining in only $41 \%$ of LCNECs.

In an effort to improve cure rates in patients with LCNEC, postoperative adjuvant chemotherapy or radiotherapy has been used in several series of this disease. , $8,18,25,26^{-1}$
Unfortunately, no study has yet reported a definitive survival advantage for postoperative adjuvant therapy in these patients. One series did find a benefit to adjuvant chemotherapy in a small subgroup of 5 patients with stage I disease treated with cisplatin, carboplatin, or cyclophosphamide. ${ }^{27}$ As a result of the small numbers in each study and the relative infrequency of LCNEC, no standard adjuvant therapy regimen has been followed. It has been suspected that these tumors are resistant to conventional chemotherapy. In a study reported by Lai and coworkers,${ }^{28}$ a majority of lung neoplasms with neuroendocrine markers were found to express the multidrug resistance gene (MDR1), a harbinger of resistance to chemotherapy. The question of the role of adjuvant therapy for early-stage LCNEC or mixed LCNEC should be answered in large-center prospective trials. A chemotherapy regimen with agents that demonstrate activity in both NSCLC and SCLC (eg, cisplatin and etoposide) should be used in these trials.

In conclusion, LCNEC of the lung is an uncommon but aggressive lung cancer associated with a poor prognosis, even in patients with stage I disease. Accurate differentiation of these tumors is important in identifying patients who are most likely to have recurrent lung cancer after surgical resection. Novel therapeutic approaches will be needed to improve cure rates in patients with this type of lung cancer.

\section{References}

1. Brambilla E. WHO 1999 classification of lung cancers: a guided tour. Ann Pathol. 1999;19(suppl):S47-9.

2. Travis WD, Linnoila RI, Tsokos MG, et al. Neuroendocrine tumors of the lung with proposed criteria for large-cell neuroendocrine carcinoma. An ultrastructural, immunohistochemical, and flow cytometric study of 35 cases. Am J Surg Pathol. 1991;15:529-53.

3. Travis WD, Rush W, Flieder DB, et al. Survival analysis of 200 pulmonary neuroendocrine tumors with clarification of criteria for atypical carcinoid and its separation from typical carcinoid. Am J Surg Pathol. 1998;22:934-44.

4. Dressler CM, Ritter JH, Patterson GA, Ross E, Bailey MS, Wick MR. Clinical-pathologic analysis of 40 patients with large cell neuroendocrine carcinoma of the lung. Ann Thorac Surg. 1997;63:180-5.

5. Jiang SX, Kameya T, Shoji M, Dobashi Y, Shinada J, Yoshimura H. Large cell neuroendocrine carcinoma of the lung: a histologic and immunohistochemical study of 22 cases. Am J Surg Pathol. 1998;22: 526-37.

6. Takei H, Asamura H, Maeshima A, et al. Large cell neuroendocrine carcinoma of the lung: a clinicopathologic study of eighty-seven cases. J Thorac Cardiovasc Surg. 2002;124:285-92.

7. Iyoda A, Hiroshima K, Toyozaki T, Haga Y, Fujisawa T, Ohwada H. Clinical characterization of pulmonary large cell neuroendocrine carcinoma and large cell carcinoma with neuroendocrine morphology. Cancer. 2001;91:1992-2000.

8. Garcia-Yuste M, Matilla JM, Alvarez-Gago T, et al. Prognostic factors in neuroendocrine lung tumors: a Spanish Multicenter Study. Spanish Multicenter Study of Neuroendocrine Tumors of the Lung of the Spanish Society of Pneumonology and Thoracic Surgery (EMETNESEPAR). Ann Thorac Surg. 2000;70:258-63.

9. Zacharias J, Nicholson AG, Ladas GP, Goldstraw P. Large cell neuroendocrine carcinoma and large cell carcinomas with neuroendocrine morphology of the lung: prognosis after complete resection and systematic nodal dissection. Ann Thorac Surg. 2003;75:348-52. 
10. Paci M, Cavazza A, Annessi V, et al. Large cell neuroendocrine carcinoma of the lung: a 10-year clinicopathologic retrospective study. Ann Thorac Surg. 2004;77:1163-7.

11. Doddoli C, Barlesi F, Chetaille B, et al. Large cell neuroendocrine carcinoma of the lung: an aggressive disease potentially treatable with surgery. Ann Thorac Surg. 2004;77:1168-72.

12. Mountain CF. Revisions in the International System for Staging Lung Cancer. Chest. 1997;111:1710-7.

13. Travis WD, Colby TV, Corrin B, Shimosato Y, Brambilla E, Collaborators from 14 Countries. World Health Organization Pathology Panel: World Health Organization. Histological typing of lung and pleural tumors. International Histological Classification of Tumors. 3rd ed. Berlin: Springer Verlag; 1999.

14. Cooper WA, Thourani VH, Gal AA, Lee RB, Mansour KA, Miller JI. The surgical spectrum of pulmonary neuroendocrine neoplasms. Chest. 2001;119:14-8.

15. Linnoila RI, Piantadosi S, Ruckdeschel JC. Impact of neuroendocrine differentiation in non-small cell lung cancer. The LCSG experience. Chest. 1994;106(suppl):367S-71S.

16. Iyoda A, Hiroshima K, Moriya Y, et al. Pulmonary large cell neuroendocrine carcinoma demonstrates high proliferative activity. Ann Thorac Surg. 2004;77:1891-5.

17. Ab' Saber AM, Massoni Neto LM, Bianchi CP, et al. Neuroendocrine and biologic features of primary tumors and tissue in pulmonary large cell carcinomas. Ann Thorac Surg. 2004;77:1883-90.

18. Rusch VW, Klimstra DS, Venkatraman ES. Molecular markers help characterize neuroendocrine lung tumors. Ann Thorac Surg. 1996;62: 798-810

19. Przygodzki RM, Finkelstein SD, Langer JC, et al. Analysis of p53, $\mathrm{K}$-ras-2, and C-raf-1 in pulmonary neuroendocrine tumors. Correlation with histological subtype and clinical outcome. Am J Pathol. 1996; 148:1531-41.

20. Papotti M, Croce S, Bello M, et al. Expression of somatostatin receptor types 2, 3 and 5 in biopsies and surgical specimens of human lung tumours. Correlation with preoperative octreotide scintigraphy. Virchows Arch. 2001;439:787-97.

21. Kwekkeboom DJ, Kho GS, Lamberts SW, Reubi JC, Laissue JA, Krenning EP. The value of octreotide scintigraphy in patients with lung cancer. Eur J Nucl Med. 1994;21:1106-13.

22. Musi M, Carbone RG, Bertocchi C, et al. Bronchial carcinoid tumours: a study on clinicopathological features and role of octreotide scintigraphy. Lung Cancer. 1998;22:97-102.

23. Filosso PL, Ruffini E, Oliaro A, Papalia E, Donati G, Rena O. Long-term survival of atypical bronchial carcinoids with liver metastases, treated with octreotide. Eur J Cardiothorac Surg. 2002;21: 913-7.

24. O’Byrne KJ, Schally AV, Thomas A, Carney DN, Steward WP. Somatostatin, its receptors and analogs, in lung cancer. Chemotherapy. 2001;47(suppl 2):78-108.

25. Travis WD, Gal AA, Colby TV, Klimstra DS, Falk R, Koss MN. Reproducibility of neuroendocrine lung tumor classification. Hum Pathol. 1998;29:272-9.

26. Hage R, Seldenrijk K, de Bruin P, van Swieten H, van den Bosch J. Pulmonary large-cell neuroendocrine carcinoma (LCNEC). Eur J Cardiothorac Surg. 2003;23:457-60.

27. Iyoda A, Hiroshima K, Toyozaki T, et al. Adjuvant chemotherapy for large cell carcinoma with neuroendocrine features. Cancer. 2001;92: 1108-12.

28. Lai SL, Goldstein LJ, Gottesman MM, et al. MDR1 gene expression in lung cancer. J Natl Cancer Inst. 1989;81:1144-50.

\section{Discussion}

Dr William H. Warren (Chicago, Ill). I think it is appropriate at this time to review some of the history of LCNEC, which dates back considerably longer than one is led to believe on the basis of the presentation and the article. In 1974, Gewirtz and Yalow extracted adrenocorticotropic hormone (ACTH) and ACTH-type substances from a large collection of primary lung carcinomas. Predictably, the majority of these cases were found to be small cell carcinomas, and many of the rest were called "carcinoids." But there are also a few LCCs from which ACTH was extracted, although their endocrine properties were not suspected clinically. This observation validated earlier case reports of the occasional LCCs presenting with so-called "ectopic" hormone production.

In 1978, Gould published a series of "undifferentiated carcinomas" identified as containing neurosecretory granules, an ultrastructural hallmark of neuroendocrine differentiation. Before this study, many of these cases were called simply "large cell undifferentiated carcinoma."

In 1982, we proposed a classification of neuroendocrine carcinomas of the bronchopulmonary tract and proposed the term "intermediate-sized cell neuroendocrine carcinoma" to describe a group of tumors (intermediate between giant cell carcinoma and small cell carcinoma) with demonstrably neuroendocrine, as well as histologic, features to distinguish them from "large cell undifferentiated carcinoma."

It has really taken 30 years for us to present an article like this, identifying the clinical significance of these well-recorded observations.

You might ask why. I can think of at least 3 reasons. First, I think LCNEC is an underdiagnosed entity. Indeed, in this series of more than 2000 cases, only 56 were identified. One reason for this, ironically, is the very lack of clinical significance. A pathologist might well argue about why one would go to the trouble of identifying this subgroup of "large cell carcinomas" if it has no clinical significance. Therefore, it has become sort of a circular argument. The second reason is this vexing problem of "multidirectional differentiation," whereby a tumor can comprised cells demonstrating simultaneously multiple lines of differentiation. This phenomenon is common among these tumors, and the authors alluded to this in their article. What do you call a lung cancer that comprises large cells, half of which have obvious glandular differentiation, adenocarcinoma, and half have demonstrably neuroendocrine differentiation? Do these tumors have a different course than those with predominantly neuroendocrine differentiation? Indeed, what percentage of the tumor has to be neuroendocrine to classify it as such? If only $10 \%$ of the cells are neuroendocrine, should this LCC be distinguished as neuroendocrine?

Last, this diagnosis can only be made currently on the basis of ideally preserved generous tissue biopsy specimens. It is now technically possible to immunostain cytologic specimens (both fine-needle aspirates and fluid samples) for panneuroendocrine markers. Can we expect the pathologist to provide this diagnosis on the basis of a minimal biopsy specimen? This goes back to my first point that this is an underdiagnosed entity.

I have several questions to pose. First, how did you identify these 56 cases (56 of more than 2000 cases)? Did you only look at LCC, or did you look at some poorly differentiated adenocarcinomas and squamous carcinomas as well?

Dr Battafarano. We looked at all the tumors that were LCCs and our prospectively gathered database, and actually it was a quite large number. It was not until we actually looked at the pathologic slides over that 14-year period that we narrowed in on those tumors that were large cell within the ones that had neuroendocrine differentiation or morphology.

Dr Warren. Can you give us any insight into your so-called mixed tumors? How much is mixed? If it is $10 \%$ neuroendocrine 
and the rest is adenocarcinoma, is that a mixed tumor? If it is $90 \%$ neuroendocrine and you find a few tonofilaments, is that neuroendocrine or mixed neuroendocrine-squamous?

Dr Battafarano. Probably less than $3 \%$ of the tumors were neuroendocrine, and they were included in there. Usually it depends on how aggressively the pathologists look. At our institution, if they find it, it probably represents a significant portion of the tumor because they are not doing millimeter slices. It might be that you would find more tumors if you sliced the tumors more carefully and really looked for it aggressively.

Dr Warren. Do you agree that this is an underestimation of this albeit unusual tumor?

Dr Battafarano. Correct.

Dr Warren. Can you comment on whether any of these cases could have been identified by minimal biopsy, such as fine-needle aspirate or a bronchial biopsy or serum neuron-specific enolase?

Dr Battafarano. We do not routinely use preoperative needle biopsy as a group, but 10 patients did have preoperative needle biopsies. In only 2 of those 10 were the tumors said to be poorly differentiated and the pathologists were concerned about neuroendocrine tumors, but they would not pin it down. For the others, there were 2 that were SCLCs that we did not believe because it presented as a solitary pulmonary nodule, and then others they just called NSCLC and would not differentiate it more closely than that.

Dr Thomas K. Waddell (Toronto, Ontario, Canada). I enjoyed that presentation, as I have the series of articles you have produced over the past couple of years.

What difference does it make once you have this information? I would like to know what lessons you have learned from your St Louis experience regarding adjuvant therapy, either adjuvant node clearance or adjuvant chemotherapy postoperatively. Finally, for the patients who do have recurrence, what information do you have about patterns of recurrence, local versus distant?

Dr Battafarano. Essentially we have taken the approach that many surgeons have taken with this, which is that there is not much you can do with it anyway, and therefore you just resect and hope for the best. But now, with these new data, I think that we can clearly tell our patients that if they have neuroendocrine differentiation in their tumor, the likelihood of development of recurrent disease and dying from that disease is quite high, and I think as a group we have to start thinking about enrolling these patients in some sort of adjuvant trial. I do not think a preoperative trial is practical because the pathologists will not give us the data we need to call it large cell neuroendocrine disease. But I think an adjuvant trial is reasonable. At the International Association for the Study of Lung Cancer last summer, we had a meeting looking at that, in which we could prospectively enroll patients. I think the adjuvant chemotherapy to use would be something like etoposide and platinum. This is something that is used in small cell carcinoma with good results, if you can call results in small cell carcinoma good, but at least there are response rates. Also, it is the etoposideplatinum that we use for our Pancoast tumors preoperatively. Therefore, it also has a reasonable response rate in patients with non-small cell cancer. Therefore, I think that that would be the thing to do.

Dr Tomasz Grodzki (Szczecin, Poland). Thank you for an extremely interesting and clinically very valuable article.You mentioned that adjuvant chemotherapy would be a solution to improve survival, but could you tell us something more about the possible mechanisms as to why such a similar carcinoma, slightly different from LCC, presents such a different prognosis?

Dr Battafarano. It is because of recurrent disease. To answer Dr Waddell's question, too, about recurrence rates, they have been local and distant, and almost all of the patients had distant recurrences at the time the disease was diagnosed. Therefore, it is not just a local problem. When they look at small cell carcinoma and compare it with LCNEC, at least at the molecular level, when you look at p53 and K-ras mutations, they are relatively similar. Therefore, I think that again for this biologic behavior in which the tumors metastasize more quickly, we assume a micrometastatic disease must be present at the time that we are redoing our resections. 